\title{
Length of Stay Children Hospitalized with Chronic Kidney Disease Based on Etiology and Stage in Dr. Hasan Sadikin Hospital Bandung, Indonesia
}

\author{
Angelreika Libowo, ${ }^{1}$ Ahmedz Widiasta, ${ }^{2}$ Dedi Rachmadi ${ }^{2}$ \\ ${ }^{1}$ Faculty of Medicine Universitas Padjadjaran, Indonesia \\ ${ }^{2}$ Department of Child Health, Faculty of Medicine Universitas Padjadjaran-Dr. Hasan Sadikin General Hospital \\ Bandung, Indonesia
}

pISSN: 2302-1381; eISSN: 2338-4506; http://doi.org/10.15850/ ijihs.v8n1.1880 IJIHS. 2020;8(1):27-31

Received:

December 20, 2019

Accepted: March 31, 2020
Abstract

Objectives: This study aims to describe the LOS children hospitalized with CKD based on the etiology and stage at Dr. Hasan Sadikin General Hospital, Bandung in 2016-2018.

Methods: This was a retrospective study with a cross-sectional design from June-October 2019. The inclusion were all medical records of pediatric inpatient diagnosed with CKD and exclusion criteria were incomplete medical record data and hospital readmission patients. The variables studied were CKD etiology, CKD stage, and length of stay

Results: From 103 patients, the etiologies found were steroid-resistant nephrotic syndrome (SRNS) (58.25\%), congenital anomalies of kidney and urinary tract $(9.71 \%)$, urinary tract infection $(5.83 \%)$, and chronic glomerulonephritis $(21.36 \%)$. The mean LOS was 19 days. The longest LOS found in CKD stage 5 patients caused by SRNS (141 days). Meanwhile, the shortest LOS was found in CKD stage 2 patients caused by chronic glomerulonephritis and CKD stage 5 patients were caused by SRNS who died (1 day).

Conclusion: Pediatric patients with CKD stage 5 with SRNS has the potential to have a longer LOS than other etiologies.

Keywords: Children, chronic kidney disease, etiology, length of stay, stages

\section{Introduction}

Chronic Kidney Disease (CKD) is an abnormal condition in the structure or function of the kidney, which occurs for more than three months, with health implications. ${ }^{1}$ CKD is classified according to decreased function of the glomerular filtration rate (GFR) and albuminuria levels. ${ }^{1}$ There are 11-12 new CKD cases per 1,000,000 children in Europe with a prevalence of 55-60 cases per 1,000,000 children. ${ }^{2}$ The incidence continues to increase compared to previous years. ${ }^{3}$

The Kidney Disease Outcomes Quality Initiative (KDOQI) divides the classification

Correspondence:

Angelreika Libowo,

Faculty of Medicine Universitas Padjadjaran, Indonesia e-mail: angelreika.libowo@yahoo.com of CKD into 5 stages. The stage of CKD is determined by the level of decline in kidney function, namely through GFR. ${ }^{4}$ GFR levels are categorized as normal if $>90 \mathrm{~mL} / \mathrm{min} / 1.73$ $\mathrm{m}^{2}$. The lower the GFR levels, the higher the CKD stages. All individuals with GFR levels $<60 \mathrm{~mL} / \mathrm{min} / 1.73 \mathrm{~m}^{2}$ for $\geq 3$ months have been diagnosed with CKD, with or without kidney damage.

The main causes of CKD in children are different from adults. In children, CKD is usually caused by congenital anomalies of the kidney and the urinary tract (CAKUT) (49.1\%), steroid-resistant nephrotic syndrome (SRNS) $(10.4 \%)$, chronic glomerulonephritis (e.g. lupus nephritis, Alport's syndrome) (8.1\%) and renal ciliopathy $(5.3 \%) .^{2}$ Some other causes of CKD in children are microangiopathic thrombosis, nephrolithiasis, Wilms tumor, infection, and others. The etiology of CKD will determine the progression of CKD severity. In 
some CKD cases, continuous kidney structure damage can cause End Stage Renal Disease (ESRD). ${ }^{6}$ Patients with ESRD conditions require renal replacement therapy (RRT) in the form of hemodialysis, peritoneal dialysis, or transplantation to stay alive. ${ }^{6}$ Patients with RRT require high costs of hospitalization. ${ }^{7}$

Data obtained in 2015 showed that Indonesian health insurance, Badan Penyelenggara Jaminan Sosial (BPJS), financing for kidney failure was IDR 2.68 trillion. ${ }^{8}$ This was ranked the second largest financing after the heart disease. ${ }^{8}$ However, there are often differences in the calculation of hospital cost which the hospital fee rates are greater than the Indonesia Case Base Groups (INA-CBGs) rates. ${ }^{9}$ Difference in rates may not be charged on patients (Kemenkes RI, 2014). If this happens continuously, it will cause harm to the hospital. The long length of stay (LOS) will add up the financial burden of health services. Identification of factors related to LOS in children with CKD, the etiology and stage of the CKD can help in determining interventions to reduce the LOS.

This study aims to look at the differences of LOS in children with CKD based on their etiology and stage of disease. From this study, it is expected to be able to provide an overview data about the LOS in CKD patients. The data can help the hospital and BPJS in determining alternative treatments that are more effective and efficient of cost by considering the LOS of pediatric patients with CKD, as well as being the basic consideration for BPJS in determining INA-CBGs rates for children with CKD patients.

\section{Methods}

This study was a retrospective study with a cross-sectional design, conducted from June to October 2019 using secondary data from the medical record database in Dr. Hasan Sadikin General Hospital, Bandung, Indonesia. The subjects of this study were pediatric patients who were hospitalized in Hasan Sadikin General Hospital, Bandung in 2016-2018. The inclusion criteria of this research were all medical records of children patients diagnosed with Chronic Kidney Disease treated in Dr. Hasan Sadikin General Hospital Bandung, Indonesia and exclusion criteria were inaccessible or incomplete registry data and hospital readmission patients.

Data was taken from the patient's medical record with total sampling method, and processed using Microsoft Excel 2010. Data collection was carried out after obtaining ethical approval number 244/UN6.C1.1/ DL/2019 by the Research Ethics Committee of Universitas Padjajaran Bandung, and Research Licensing Letter issued by the Research Ethics Committee of Dr. Hasan Sadikin General Hospital Bandung (No. LB.02.01/X.2.2.1/10525/2019). The selected data will be presented in the table to illustrate the difference in LOS.

\section{Results}

Based on the list of names given from the medical record database, the total pediatric CKD patients who were hospitalized in Dr.

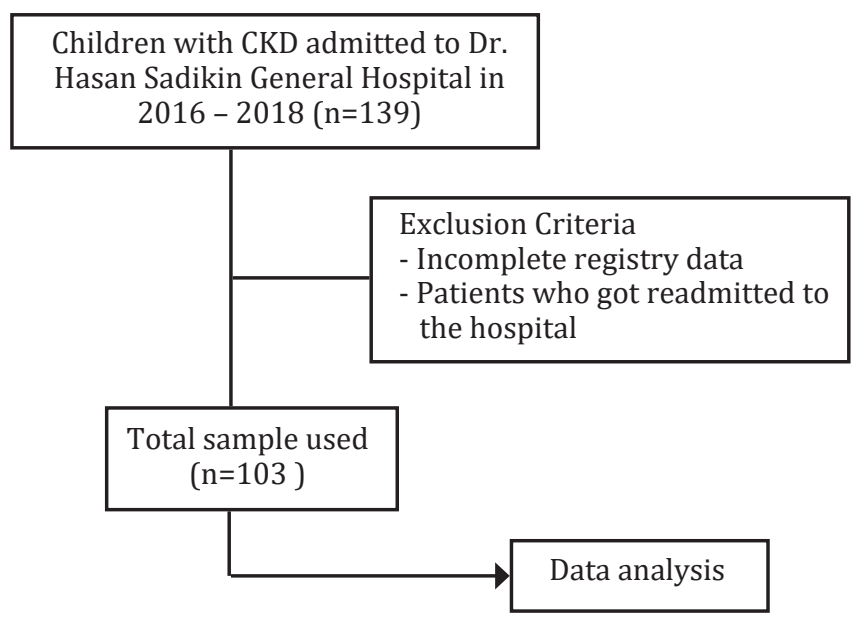

Fig. Diagram of Subject Selection 
Table 1 Characteristics of Children with CKD

\begin{tabular}{lcc}
\hline \multicolumn{1}{c}{ Characteristics } & $\mathbf{( n = 1 0 3 )}$ & $\mathbf{\%}$ \\
\hline Sex & & \\
$\quad$ Male & 56 & 54.37 \\
Female & 47 & 45.63 \\
Age Group & & \\
$\quad$ 1-5 years & 9 & 8.74 \\
6-9 years & 11 & 10.68 \\
10-18 years & 83 & 80.58 \\
Funding Sources & & \\
$\quad$ Private & 7 & 6.80 \\
BPJS Non-PBI & 55 & 53.40 \\
$\quad$ BPJS PBI & 34 & 33.01 \\
$\quad$ Hospital subsidy & 7 & 6.80 \\
\hline
\end{tabular}

Hasan Sadikin General Hospital, Bandung in the study period was 139 people, but there were 7 inaccessible data. There were 103 data meet the inclusion criteria from 132 data that have been collected. A total of 29 data were excluded because they were patients with readmission hospitalization.
Characteristics of pediatric CKD patients treated at Dr. Hasan Sadikin General Hospital can be seen in Table 1 . Out of 103 patients, the majority of the patients were male $(54.37 \%)$, adolescent (80.58\%), and had funding sources from BPJS (86.41\%), which includes BPJS nonPBI $(53.40 \%)$ and PBI (33.01\%). The oldest patient in this study was 18 years old and the youngest one was 1 year old with an average age of 12 years.

In this study, the most frequent etiology was SRNS. The longest LOS in this group was 141 days with an average LOS of 22 days. Patients with CAKUT were mostly hospitalized for 8-14 days $(40.0 \%)$. While most of the patients with chronic glomerulonephritis were hospitalized for $\leq 7$ days $(40,91 \%)$. Half of the patients with urinary tract infection (UTI) had to be hospitalized for 15-21 days. Patients with other etiology such as renal tuberculosis mostly had LOS in the 8-14 days group $(60.0 \%)$. Overall, the mean LOS in all patients was 19 days with the longest LOS was 141 days in patients with SRNS. The shortest LOS was found in patients with CKD stage 2 caused by chronic glomerulonephritis who got hospitalized for 1 day and patient with CKD

Table 2 Length of Stay of Children with CKD based on Etiology

\begin{tabular}{|c|c|c|c|c|c|}
\hline \multirow[b]{2}{*}{ Characteristics } & \multicolumn{5}{|c|}{ CKD Stages $(n=103)$} \\
\hline & $\begin{array}{l}\text { CAKUT } \\
\text { n (\%) }\end{array}$ & $\begin{array}{l}\text { SRNS } \\
\text { n (\%) }\end{array}$ & $\begin{array}{c}\text { Chronic } \\
\text { Glomerulo- } \\
\text { nephritis } \\
\text { n (\%) }\end{array}$ & $\begin{array}{c}\text { Urinary } \\
\text { Tract } \\
\text { Infection } \\
\text { n (\%) }\end{array}$ & $\begin{array}{c}\text { Others } \\
\text { n (\%) }\end{array}$ \\
\hline Length of Stay & & & & & \\
\hline$\leq 7$ days & $2(20.0)$ & $18(30.0)$ & $9(40.91)$ & $1(16.67)$ & $1(20.0)$ \\
\hline 8-14 days & $4(40.0)$ & $10(16.67)$ & $3(13.64)$ & $1(16.67)$ & $3(60.0)$ \\
\hline 15-21 days & $1(10.0)$ & 7 (11.67) & $7(31.81)$ & $3(50.0)$ & $0(0.0)$ \\
\hline $22-28$ days & $1(10.0)$ & $8(13.33)$ & $1(4.55)$ & $1(16.67)$ & $0(0.0)$ \\
\hline$>28$ days & $2(20.0)$ & 17 (28.33) & $2(9.09)$ & $0(0.0)$ & $1(20.0)$ \\
\hline
\end{tabular}

Tabel 3 Length of Stay of Children with CKD based on Stage

\begin{tabular}{lccccc}
\hline \multirow{2}{*}{ Characteristics } & \multicolumn{5}{c}{ CKD Stages (n=103) } \\
\cline { 2 - 6 } & $\begin{array}{c}\text { Stage 1 } \\
\text { n (\%) }\end{array}$ & $\begin{array}{c}\text { Stage 2 } \\
\text { n (\%) }\end{array}$ & $\begin{array}{c}\text { Stage 3 } \\
\text { n (\%) }\end{array}$ & $\begin{array}{c}\text { Stage 4 } \\
\text { n (\%) }\end{array}$ & $\begin{array}{c}\text { Stage 5 } \\
\text { n (\%) }\end{array}$ \\
\hline $\begin{array}{l}\text { Length of Stay } \\
\text { 57 days }\end{array}$ & $6(60.0)$ & $1(50.0)$ & $2(40.0)$ & $1(50.0)$ & $21(25.0)$ \\
8-14 days & $0(0.0)$ & $1(50.0)$ & $1(20.0)$ & $1(50.0)$ & $18(21.43)$ \\
15-21 days & $3(60.0)$ & $0(0.0)$ & $1(20.0)$ & $0(0.0)$ & $14(16.67)$ \\
22-28 days & $0(0.0)$ & $0(0.0)$ & $1(20.0)$ & $0(0.0)$ & $10(11.90)$ \\
$>$ 28 days & $1(10.0)$ & $0(0.0)$ & $0(0.0)$ & $0(0.0)$ & $21(25.0)$ \\
\hline
\end{tabular}


stage 5 caused by SRNS who died.

Research data shows that from 103 patients, 84 of them suffered CKD stage 5 . The majority of CKD patients have LOS in the category $\leq 7$ days (60\%). Similarly, in patients with CKD stages 2,3 , and 4 , the most LOS is $\leq 7$ days which is $50 \%, 40 \%$, and $50 \%$, respectively. Whereas patients with CKD stage 5 have an equivalent percentage in the $\leq 7$ days and $>28$ days category, which is $25 \%$. Patients with CKD stage 5 have an average LOS of 21 days with the longest stay was 141 days.

\section{Discussion}

In this study we found that children with CKD were more prevalent in males $(54,35 \%)$. This finding is similar to the previous studies conducted by Becherucci et al. ${ }^{2}$ This is due to the higher incidence of congenital disorders, one of the most common etiology of CKD in children, including obstructive uropathy and renal dysplasia in males than in females. ${ }^{10}$ Similarly, the prevalence of ESRD was more prevalent in males than females. This data is in accordance with a previous study which states that the progression of CKD in men is faster than in women. ${ }^{11,12}$ This is likely caused by estrogen hormone in female which act as a protective agent, while in men there is the testosterone hormone which is damaging to the kidneys. ${ }^{12}$

The incidence of CKD increases with age. $80,58 \%$ of the patients were in the $10-18$ years age group with the most common etiology was SRNS. This is similar to the data obtained from 14 Educational Hospitals with Children's Nephrology Consultants (2017). In patients aged 1-5 years old, the most common etiology was CAKUT. This is in accordance with a study that has been done previously in Tunisia. ${ }^{13}$

The etiologies of pediatric CKD patients in this study were SRNS, CAKUT complicated by UTI, and chronic glomerulonephritis. SRNS patients need time for hemodynamic stabilization of the patient, diagnosis, and administration of chemotherapy. ${ }^{14}$ However, the process of finding the best therapy for patients with SRNS is individual, so the duration of LOS and the outcome of each patient can be different. ${ }^{14}$ The LOS of patients with CAKUT in this study were mostly in the 8-14 days category (40\%). Patients with congenital anomalies will undergo the correction procedure for these abnormalities. ${ }^{15}$ In patients with CAKUT who complicated by UTI, patients need time to manage the UTI that require a minimum of
10 days for antibiotics, and a minimum of 3-7 days to obtain urine culture results. Imaging examinations (radiology) are also needed to establish the diagnosis and determine the next steps of management. ${ }^{15}$ As for patients with an initial etiology of UTI, the bacterial culture will be performed on patients and then given antibiotics. Chronic glomerulonephritis also requires a quite long hospitalization, but not requires chemotherapy or surgery.

The LOS of children with stage 5 CKD is mostly in $\leq 7$ days and $>28$ days category. The difference was caused by the condition of some patients who experienced hemodynamic instability so the doctor must wait for the patient to return stable to start the treatment. In addition, the setting-up device for hemodialysis or peritoneal dialysis will take several days. This will complicate the treatment process and have an impact on the LOS of the patient. However, not all CKD stage 5 patients experience this condition so that the doctor can start kidney replacement therapy and send the patient home when his condition has improved. Some of the patients with CKD stage 5 admitted because the doctors found other disorders, such as anemia and pulmonary edema during hemodialysis. In this condition, the patient needs to be hospitalized for a few days until the patient gets better. Eighteen patients with CKD stage 5 died in this study, either by the progression of the disease or by the other comorbid the patients had. Death is one of the factors that affect the LOS, which can reduce the duration of stay.

The LOS in patients with CKD stage 2, 3, and 4 were not as long as patients with CKD stage 5 . The majority of first-stage CKD patients were hospitalized for $\leq 7$ days because generally, the patient is not in life-threatening condition, so patients can be discharged immediately after being treated. In those patients, clinical monitoring will be carried out in the form of vital signs and supporting examinations to determine the patient's overall condition. If the patient is found contraindicated for treatment (anemia, leucopenia, thrombocytopenia), then the correction will be carried out first before starting therapy.

In addition to the etiology and stage of the disease, there are other factors influence the LOS of patients with CKD in children. In this study, several patients went home before achieving recovery for various reasons both financial and family reasons. This is supported by Nursalam's study which states the reason for leaving a patient can affect the LOS of the patient. Other studies also confirmed that 
patient condition at discharge affected LOS. ${ }^{16}$ In the present study, the patient's condition at discharge was unclear because it was not stated in the medical record, unless if the patient dies. This may affect the LOS of patients in this study.

In the patient funding source data, the majority of patients pay with governmental insurance (BPJS), PBI and non-PBI. A study in Iran states that the method of payment affects the LOS of patients with the results of patients who use health insurance have a longer stay than patients with independent payments..$^{17,18}$

The limitation of this study is inaccessible registry data from the hospital system due to the transfer of paper-based data to paperless. Besides, the limited time of the study also caused a reduction in the sample taken in this study, causing an uneven distribution of the number of members in each group of data.

For further research it is recommended

\section{References}

1. KDIGO. Clinical practice guideline update for the diagnosis, evaluation, prevention, and treatment of chronic kidney disease. Kidney Int Suppl. 2017;7(3):e1.

2. Becherucci F, Roperto RM, Materassi M, Romagnani P. Chronic kidney disease in children. Clin Kidney J. 2016;9(4):583-91.

3. Wong CJ, Moxey-Mims M, Jerry-Fluker J, Warady AB, L. Furth S. CKiD (CKD in Children). NIH Public Access. 2013;60(6):1002-11.

4. Initiative NKF (NKF) KDQ. Clinical Practice Guidelines. New York: National Kidney Foundation; 2002.

5. Pardede SO, Chunnaedy S. Penyakit ginjal kronik pada anak. Sari Pediatr. 2017;11(3):199.

6. Couser WG, Remuzzi G, Mendis S, Tonelli M. The contribution of chronic kidney disease to the global burden of major noncommunicable diseases. Kidney Int. 2011;80(12):1258-70.

7. El Nahas AM, Bello AK. Chronic kidney disease: The Global Challenge. Lancet. 2005;365 (9456):331-40.

8. Kemenkes RI. Situasi penyakit ginjal kronis. Pus Data dan Inf Kementerian Kesehatan RI. 2017.

9. Azalea M, Andayani TM. Analisis biaya pengobatan penyakit ginjal kronis rawat inap dengan hemodialisis di rumah sakit. J Manaj dan Pelayanan Farm. 2016;141-50.

10. Warady BA, Chadha V. Chronic kidney disease in children: the global perspective. Pediatr Nephrol. 2007;22(12):1999-2009. that the recording of data registers can be done more carefully. Besides, further research is expected to increase the number of samples by extending the period so that the data collected can better present each group of data. A multicentre study in various regions is also needed to obtain data that better represents the LOS of pediatric CKD patients throughout Indonesia.

It can be concluded that from 103 patients with CKD at Dr. Hasan Sadikin General Hospital Bandung in the 2016-2018 period, the majority of the patients are male, adolescent, and have sources of funding from BPJS, PBI and non-PBI. CKD with SRNS has the potential to prolong the LOS, so the patients will need greater costs. In patients with CKD stage 5, the duration of LOS is longer because most patients experience hemodynamic disorders that require stabilization before starting treatment.

11. Goldberg I, Krause I. The role of gender in chronic kidney disease. Eur Med J. 2016;1(2):58-64.

12. Carrero JJ, Hecking M, Chesnaye NC, Jager KJ. Sex and gender disparities in the epidemiology and outcomes of chronic kidney disease. Nat Publ Gr. 2018; Available from: http://dx.doi. org/10.1038/nrneph.2017.181

13. Maalej B, Louati H, Guirat R, Wali M, Abid H, Jallouli $\mathrm{M}$, et al. Childhood chronic kidney disease. iMedPub Journals. 2018;2(1);1-3.

14. Nourbakhsh N, Mak RH. Steroid-resistant nephrotic syndrome: past and current perspectives. Pediatric Health Med Ther. 2017; 8:29-37.

15. Sahay M. Congenital anomalies of kidney and urinary tract. Clin Queries Nephrol. 2013;2(4):156-65.

16. Sepehri A, Simpson W, Sarma S. The influence of health insurance on hospital admission and length of stay-The case of Vietnam. Soc Sci Med. 2006;63(7):1757-70.

17. Khosravizadeh O, Vatankhah S, Bastani P, Kalhor R, Alirezaei S, Doosty F. Factors affecting length of stay in teaching hospitals of a middle-income country. Electron Physician. 2016;8(10):30423047.

18. Gohari M, Vahabi N, Moghadamifard Z. Semi-parametric Cox regression for factors affecting hospitalization length. Daneshvar Pezeshki. 2012;19(99):23-30. 